\title{
Erratum
}

\section{Expressing glomerular filtration rate in children}

\author{
David C. Heilbron', Malcolm A. Holliday², Amira Al-Dahwi2, and Barry A. Kogan ${ }^{3}$ \\ Departments of ${ }^{1}$ Epidemiology and Biostatistics, ${ }^{2}$ Pediatrics, and ${ }^{3}$ Urology, University of California, San Francisco, \\ San Francisco, cA 94 143-0704, USA
}

Received November 8, 1989; received in revised form March 27, accepted July 2, 1990

The above-mentioned article in volume 5, issue 1, 1991, contains a typesetting error.

The equation on page 6 under the section "Patients and Methods" should read:

Surface area $=$ Height $(\mathrm{cm}) 0.3964 \times$ Weight $(\mathrm{kg}) 0.5378 \times 0.024265$ (1) 